\title{
Fusion researchers seek US role as partner in EU's JET facility
}

[WASHINGTON] A group of prominent US fusion scientists has suggested that the United States should try to become a partner in the European Union's Joint European Torus (JET) in the United Kingdom to gain greater access to the world's largest research facility for plasma physics.

The six physicists include the directors of the three main US centres for magnetic fusion research, at Princeton, San Diego and the Massachusetts Institute of Technology. They argue that formal US involvement in JET would improve their ability to use the UK facility to test and refine computer-based models for plasma confinement.

The idea has been put forward at a critical time, as the US government is in the process of deciding how to realign its fusion programme when a major international collaboration is completed next summer. The design phase of the International Thermonuclear Experimental Reactor (ITER), which absorbs about $\$ 85$ million of the US Department of Energy's \$230 million fusion budget, ends next July.

But the suggestion that the United States should offer to join JET at this stage has angered supporters of ITER on both sides of the Atlantic. They see it as a thinly disguised attempt to map out an alternative path for international collaboration in fusion research if ITER is not built.

The four ITER partners - Europe, the United States, Russia, and Japan — remain committed in principle to negotiating the construction of the machine next year, although the United States has already said that it will not play a large part in ITER construction, which is expected to be delayed (see Nature 387, 746; 1997).

The physicists presented their proposal to join JET last month to a subpanel of the Fusion Energy Sciences Advisory Council (FESAC), the external body that advises the Department of Energy on how to run the programme. It is contained in a report on US strategy for exploring the science and technology of energy-producing plasmas.

The report recommends "support of ongoing ITER design and analysis, at a reduced level". But it also advocates "strongly increased US participation" at JET and at the Japanese facility, JT-60U. "We recommend that the US negotiates with Euratom for partnership status in JET," the proposal says.

Its authors, however, now concede that their call for negotiation was premature. "We meant to say 'explore", says David Baldwin, vice-president of fusion at General Atomics in San Diego, and the proposal's lead author.
Baldwin says that the proposal is not intended to divert resources from ITER, but to use JET to further refine the ITER design. He says that as well as supporting ITER, the US needs to undertake "dual-purpose" collaborative work that would advance fusion science in general, because Congress is unlikely to support further US contributions for ITER alone.

Hermann Grunder, director of the Thomas Jefferson National Accelerator Facility in Virginia and chair of the FESAC subpanel, says that FESAC strongly supported the strategic plan document. "JET is the one remaining facility that can give us scientific information on the burning of D-T plasma, in support of ITER," he says.

But his panel did not take up the recommendation to join JET. "It is a political hot potato, and we don't want to offend any of our European colleagues," says Grunder.

Charles Baker, the head of the US team working on the ITER design, says that extra US involvement at JET would be counterproductive if it also cut back on its involvement in ITER, as JET's research programme is devoted to supporting ITER.

At a full meeting of FESAC earlier this week, the Grunder panel proposed allocating between $\$ 10$ million and $\$ 20$ million of the $\$ 55$ million now spent on ITER on physics collaboration at JET and JT-60U. The panel suggested that all but $\$ 15$ million of the US ITER money be spent on activities other than refining the current ITER design, including \$5 to \$10 million for "lower cost concepts" for achieving plasma burn.

Several FESAC members criticized the Grunder report, and the full panel, chaired by John Sheffield of Oak Ridge National Laboratory, was expected to back an interim plan more supportive of ITER than Grunder's. Francis Troyon, the chairman of the JET council, sent a message to Sheffield on Monday warning the United States that JET is busy with ITER-related experiments until 1999, and that thereafter "the future of JET is closely tied to that of ITER".

But Alan Gibson, deputy director of JET, says that informal discussions have already taken place about US membership of the facility, and adds that a formal proposal "of mutual benefit" would be welcomed. He says JET officials are keen to extend its operating life beyond 1999, but their plans are hampered by a shortage of funds. Colin Macilwain

\section{Cassini mission blasts off for Saturn}

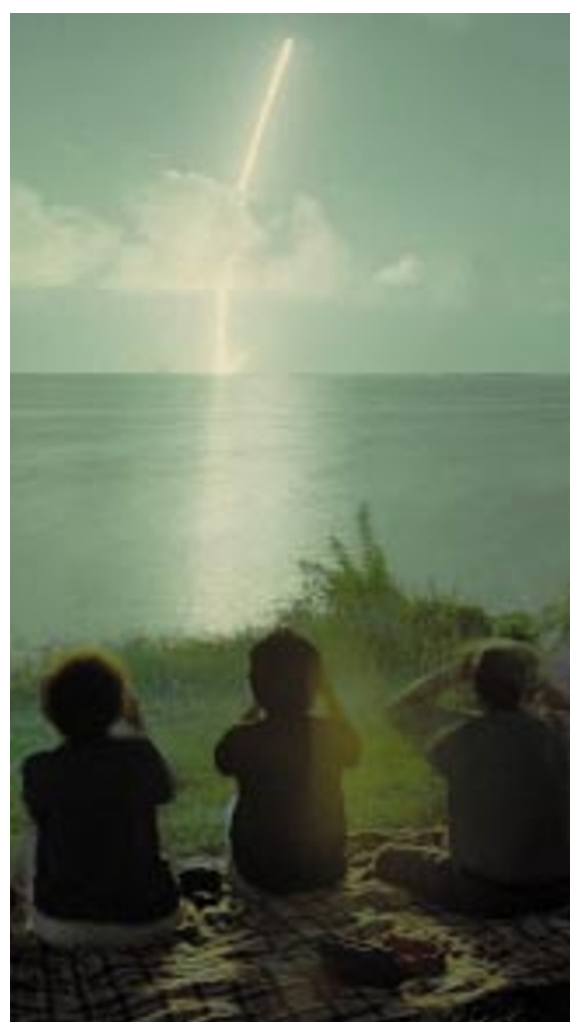

[WASHINGTON] Cassini, the most ambitious and expensive planetary expedition ever mounted, began its long trip to Saturn from Cape Canaveral, Florida, on 15 October (left). The spacecraft, which is costing the US, European and Italian space agencies $\$ 3.3$ billion to build, launch and operate, will arrive at Saturn in July 2004. It will orbit the planet for four years, investigating its atmosphere, moons, rings and electromagnetic fields.

In November 2004, the European-built Huygens probe will detach from the main ship and land on the large moon Titan, taking pictures and data as it parachutes through the thick atmosphere. Huygens is the European Space Agency's first planetary lander and the first designed to touch down on the satellite of another planet apart from Earth.

As a money-saving measure, Cassini will skimp on science during the first five years of its journey to Saturn, when it will swing past Venus, Earth and Jupiter to gain velocity. Unlike the Galileo Jupiter mission, Cassini's 12 science experiments will be turned off except for a gravitational wave detection experiment and occasional instrument health checks. Tony Reichhardt 